\title{
Glutamatergic alterations in the cortex of genetic absence epilepsy
}

\section{rats}

\author{
Monique Touret*1, Sandrine Parrot ${ }^{2}$, Luc Denoroy ${ }^{3}$, Marie-Françoise Belin ${ }^{1}$ \\ and Marianne Didier-Bazes ${ }^{1}$
}

Address: 'INSERM, U842, Lyon; Université de Lyon, Lyon1, Faculté de Médecine Laennec, UMR-S842, Lyon, F-69372, France, ${ }^{2}$ Neurochem, Université de Lyon, Lyon1, Faculté de Pharmacie, Lyon 1 France and ${ }^{3}$ CNRS FRE 3006, Lyon; Université de Lyon, Lyon1, Faculté de Pharmacie, Lyon 1 France

Email: Monique Touret* - touret@univ-lyon1.fr; Sandrine Parrot - sparrot@sante.univ-lyon1.fr; Luc Denoroy - denoroy@sante.univ-lyon1.fr; Marie-Françoise Belin - belin@laennec.univ-lyon1.fr; Marianne Didier-Bazes - bazes@msn.com

* Corresponding author

Published: 29 August 2007

BMC Neuroscience 2007, 8:69 doi:10.1/86/147|-2202-8-69
Received: 19 December 2006

Accepted: 29 August 2007

This article is available from: http://www.biomedcentral.com/I47I-2202/8/69

(C) 2007 Touret et al; licensee BioMed Central Ltd.

This is an Open Access article distributed under the terms of the Creative Commons Attribution License (http://creativecommons.org/licenses/by/2.0), which permits unrestricted use, distribution, and reproduction in any medium, provided the original work is properly cited.

\begin{abstract}
Background: In absence epilepsy, the neuronal hyper-excitation and hyper-synchronization, which induce spike and wave discharges in a cortico-thalamic loop are suspected to be due to an imbalance between GABA and glutamate (GLU) neurotransmission. In order to elucidate the role played by GLU in disease outcome, we measured cortical and thalamic extracellular levels of GLU and GABA. We used an in vivo quantitative microdialysis approach (no-net-flux method) in an animal model of absence epilepsy (GAERS). In addition, by infusing labelled glutamate through the microdialysis probe, we studied in vivo glutamate uptake in the cortex and thalamus in GAERS and non-epileptic control (NEC) rats. Expression of the vesicular glutamate transporters VGLUTI and VGLUT2 and a synaptic component, synaptophysin, was also measured.

Results: Although extracellular concentrations of GABA and GLU in the cortex and thalamus were not significantly different between GAERS and NEC rats, cortical GLU uptake was significantly decreased in unrestrained awake GAERS. Expression of VGLUT2 and synaptophysin was increased in the cortex of GAERS compared to NEC rats, but no changes were observed in the thalamus.

Conclusion: The specific decrease in GLU uptake in the cortex of GAERS linked to synaptic changes suggests impairment of the glutamatergic terminal network. These data support the idea that a change in glutamatergic neurotransmission in the cortex could contribute to hyperexcitability in absence epilepsy.
\end{abstract}

\section{Background}

Generalized absence seizures, mainly seen in childhood, are characterized by loss of consciousness associated with bursts of bilaterally synchronous spike and wave discharges (SWDs). The Genetic Absence Epilepsy Rat from Strasbourg (GAERS) $[1,2]$ is recognized as a valid tool for investigating the human disorder. These rats develop spontaneous absence seizures at about postnatal day 40 that persist throughout life. As in the human disease, the SWDs in GAERS are generated in a cortico-thalamic loop involving reciprocal glutamatergic projections and gamma amino butyric acid (GABA) inter-neurons [2]. Several electrophysiological and pharmacological studies have suggested the involvement of GABA and glutamate 
(GLU) in the initiation and spreading of SWDs [2], with a predominant role of GABA. Although no obvious anatomical differences in these two systems have been reported in GAERS compared to non-epileptic control (NEC) rats, increased extracellular GABA levels in the thalamus and cortex [3] and reduced GABA uptake in thalamic synaptosomes [4] have been reported in GAERS. As regards the glutamatergic system, we previously observed deregulation of the metabolism of GLU and its membrane transporters in the cortex and/or thalamus of young GAERS before the occurrence of seizures [5,6], suggesting an early impairment of the GLU neuro-circuitry, which may be involved in the genesis of the pathology. In adult rats, electrophysiological studies have demonstrated an increased response to NMDA and non-NMDA glutamatergic receptor activation in the cortex of GAERS compared to NEC rats [7], which may play a major role in the control of absence seizures in the thalamus [8]. Furthermore, we, and others found deregulation of GLU metabolism [9,5] and perturbation of membrane transporter gene expression [6] in the cortex. However, the in vivo consequences of these perturbations on basal levels of GLU and its clearance from the extracellular space are not known.

In order to understand the involvement of GLU in the genesis of SWDs, we measured basal extracellular GLU and GABA levels in GAERS and NEC rats. We also evaluated GLU transport capacity using an in vivo microdialysis approach in awake animals. Furthermore, we investigated possible alterations in glutamatergic terminals in the GAERS cortex and thalamus by studying the expression of the neuronal GLU vesicular transporters VGLUT1 and VGLUT2 [10], and of synaptophysin, one of the most abundant proteins in synaptic vesicles, used as a marker of terminals $[11,12]$.

\section{Results}

\section{Microdialysis experiments}

The microdialysate values $\left(\mathrm{C}_{\text {dial }}\right)$ obtained when no exogenous GLU or GABA was perfused through the probe did not differ between NEC rats and GAERS in either the thalamus or cortex (Table 1). The true extracellular concentrations $\left(\mathrm{C}_{\text {ext }}\right)$, which reflect in vivo release and uptake processes, were also determined using the no-net flux method. In the two structures studied no difference between NEC rats and GAERS was seen for GLU and GABA (Table 1). However, a difference in the variance (F37.1, $\mathrm{p}=0.041$ ) of GLU values have been observed in the cortex between GAERS, and NEC, suggesting a possible instability of excitation only present in the cortex of epileptic rats.

\section{Estimation of GLU uptake using exogenous radioactive GLU}

In the cortex, GLU uptake was lower in GAERS than in NEC rats (Student's t test, ${ }^{*} \mathrm{p}<0.05$ ) when a mixed solution of labeled MAN and GLU was perfused (Figure 1A). In the presence of $20 \mathrm{mmol} / \mathrm{L}$ THA, a GLU uptake blocker, GLU uptake was reduced and the difference between the two strains disappeared (Figure 1B). When the same experiment was carried out in the thalamus, no difference was seen between GAERS and NEC rats either in the presence or absence of uptake inhibitor (Figure 1C,D).

\section{Western blot analysis}

VGLUTI expression

Quantification of the immunolabeled band at the expected molecular weight of about $59 \mathrm{kDa}$ revealed no difference in protein levels in either the thalamus or cortex between GAERS and NEC rats (Figure 2).

\section{VGLUT2 expression}

When the immunolabeled band at the expected molecular weight of about $62 \mathrm{kDa}$ was quantified, an increase in protein levels $(37 \% \mathrm{P}<0.01)$ was seen in the cortex, but not the in thalamus, in GAERS compared to NEC rats (Figure 2).

\section{Synaptophysin expression}

When the immunolabeled band found at the expected molecular weight of about $38 \mathrm{kDa}$ was quantified, a significant increase $(21 \%, \mathrm{p}<0.05)$ was seen in the cortex, but not in the thalamus, in GAERS compared to NEC rats (Figure 3).

\section{Discussion and conclusion}

The identification of the biochemical and anatomical targets impaired in absence epilepsy is crucial to the understanding of the genesis of the disease and for focusing therapy. The present work provides biochemical data suggesting an alteration in GLU transmission, restricted to the cortex of GAERS. These data are in accordance with previous studies demonstrating: a) a primary role of corticothalamic neurons in the synchronized excitation of thalamic relay and reticular neurons in GAERS [13], b) initiation of the paroxysmal oscillation by a cortical focus in WAG/Rij rats, another model of absence epilepsy [14], and, c) immediate cessation of SWD on applying the anti-absence drug, ethosuximide, to a focalized zone in the cortex, but not the thalamus, in GAERS [15].

Using an in vivo approach, we demonstrated decreased GLU uptake in the cortex of unrestrained awake adult GAERS. In contrast, quantitative in vivo microdialysis failed to show any significant change in basal GABA or GLU extracellular levels in GAERS in the two structures involved in SWD (thalamus and cortex). However, the 
Table I: Comparison of extracellular levels $\left(C_{\text {ext }}\right.$, i.e. $\left.C_{i n}=C_{\text {out }}\right)$, microdialysate concentrations ( $C_{\text {dial }}$, i.e. $C_{\text {in }}=0$ mol/L), and in vivo extraction efficiency (Ed) i.e. slope of $C_{i n}-C_{\text {out }}$ vs $C_{i n}$ ) of GLU and GABA determined by the "no net flux" method (for details, see Methods) in absence epilepsy rats (GAERS strain) and non-epileptic Wistar (NEC) rats

\begin{tabular}{|c|c|c|c|c|}
\hline & \multicolumn{2}{|c|}{ GLU $(\mu \mathrm{mol} / \mathrm{L})$} & \multicolumn{2}{|c|}{ GABA (nmol/L) } \\
\hline & GAERS & NEC & GAERS & NEC \\
\hline Cortex & (5) & (5) & (5) & (5) \\
\hline $\mathrm{C}_{\mathrm{ext}}$ & $1.67 \pm 0.44$ & $0.91 \pm 0.01$ & $18.1 \pm 8.1$ & $16 \pm 6.1$ \\
\hline$C_{\text {dial }}$ & $0.78 \pm 0.10$ & $0.68 \pm 0.1$ & $10 \pm 3.0$ & $12.5 \pm 4.2$ \\
\hline Ed & $0.59 \pm 0.18$ & $0.76 \pm 0.10$ & $0.67 \pm 0.12$ & $0.82 \pm 0.05$ \\
\hline Thalamus & (5) & (6) & (5) & (6) \\
\hline $\mathrm{C}_{\text {ext }}$ & $3.31 \pm 146$ & $4.82 \pm 1.90$ & $18.5 \pm 4.4$ & $14.1 \pm 1.9$ \\
\hline $\mathrm{C}_{\text {dial }}$ & $1.94 \pm 0.78$ & $2.26 \pm 0.96$ & $15.0 \pm 3.3$ & $12.5 \pm 2.4$ \\
\hline Ed & $0.63 \pm 0.1$ & $0.47 \pm 0.08$ & $0.83 \pm 0.05$ & $0.87 \pm 0.09$ \\
\hline
\end{tabular}

Number of rats per group in brackets

variances for the GLU values were larger in the cortex of GAERS, but not in the thalamus, suggesting, an instability in glutamate excitation restricted to the cortex in epileptic rats. However, SWDs were present in some of the time intervals in which the microdialysis samples were collected, but not in others, which might increase the variability of the GLU. Further studies taking into account this experimental aspect by performing sub-minute sampling during brain microdialysis will be of interest to more precisely describe alterations in extracellular GLU in the cortex

of

GAERS.

The lower in vivo GLU uptake in the cortex of GAERS may be due to an impairment of GLU transporters in astrocytes. These cells are a major contributor to the clearance of extracellular GLU via two main glial transporters,
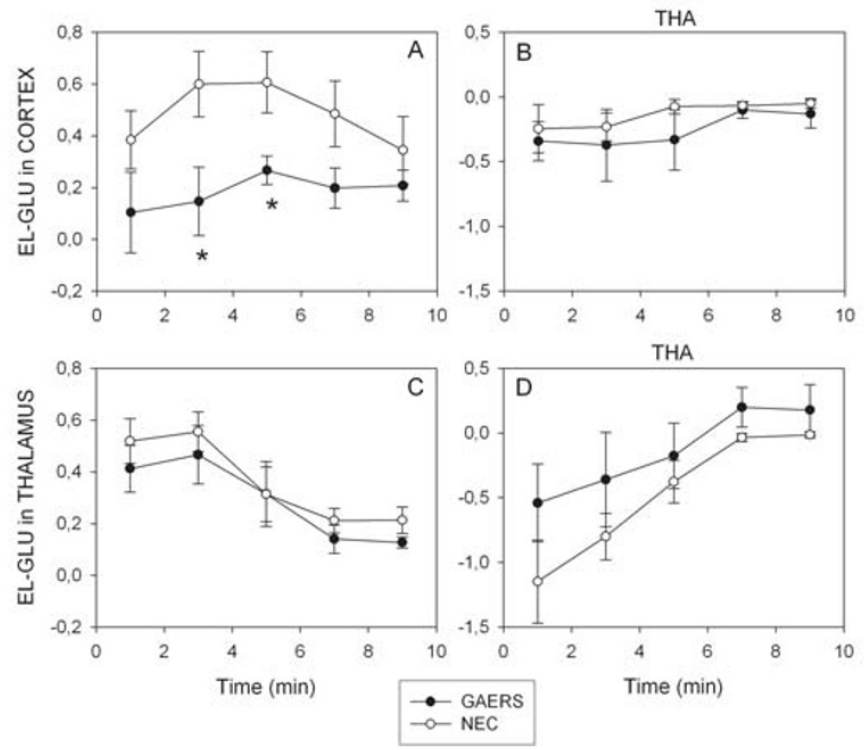

\section{Figure I}

Uptake of exogenous radioactive GLU in the cortex of GAERS $(n=6)$ and NEC rats $(n=6)$ and thalamus of GAERS $(n=6)$ and NEC rats $(n=6) .250 \mu M{ }^{3} \mathrm{H}-\mathrm{GLU}$ and $120 \mu \mathrm{M}{ }^{14} \mathrm{C}-\mathrm{MAN}$ were infused for $10 \mathrm{~min}$ with or without $20 \mathrm{mM}$ THA and microdialysis samples collected every $2 \mathrm{~min}$. The results, expressed as the mean $\pm \mathrm{SEM}$, are plotted as the extraction fraction $\mathrm{E}_{\mathrm{L}-\mathrm{GLU}}$, versus time 


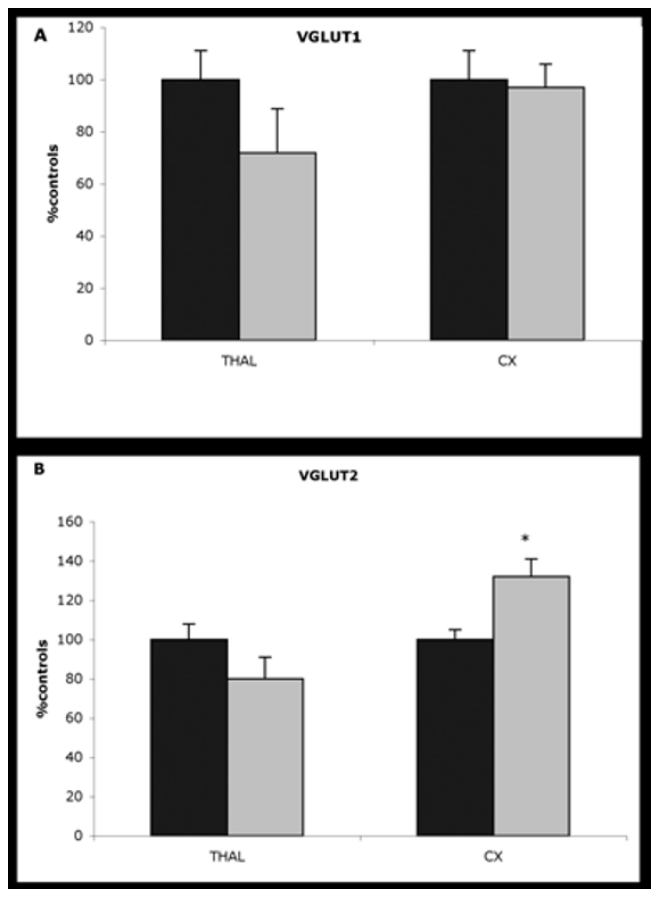

\section{Figure 2}

Expression of vesicular GLU transporter proteins in the cortex and thalamus of adult GAERS (grey bars) and NEC controls (hatched bars). Homogenates were subjected to SDSPAGE and immunoblotted with anti-VGLUTI (A) or antiVGLUT2 (B) antibodies. The relative quantification was performed using a fluorimager. The results are represented as a percentage of the value in NEC rats (mean \pm SEM; $n=6$ ). Values were compared to control rat values with a twotailed Student's t test $\left({ }^{*} p<0.05\right)$

GLAST and GLT1, which are situated in the vicinity of the synaptic cleft and play a crucial physiological role in the normal functioning of neurons $[16,17]$. In a previous study [6], we found decreased levels of GLAST mRNA in the cortex of adult GAERS, without a similar change in protein expression. This could reflect impairment of the transcription and/or turnover of GLAST protein, leading to the lower level of GLU uptake seen in the present study by in vivo microdialysis. From a physiological point of view, this lack of GLU reuptake could favor spillover of the neurotransmitter outside the synaptic cleft and this could be involved in the neuronal synchronization and firing amplification giving rise to SWDs.

The second main finding of the present work was increased VGLUT2 expression in the cortex of adult GAERS, but not in the thalamus, while VGLUT1 expression appeared normal. Interestingly in normal adult rat brain, VGLUT2 protein expression is mainly restricted to

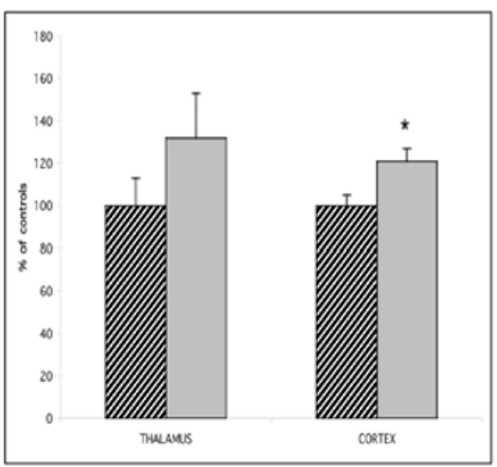

Figure 3

Expression of synaptophysin protein in cortex and thalamus of adult GAERS (grey bars) compared to controls (NEC) (hatched bars). Sample homogenates were subjected to SDSPAGE and immuno-blotted with anti-synaptophysin antibodies. The relative quantification was performed by a fluorimager. The results are represented as a mean percentage of control rats \pm SEM. GAERS values $(n=6)$ were compared to control rat values $(n=6)$ with a two-tailed Student's T test $(* p<0,05)$

lamina IV of the neo-cortex, while its mRNA is found in the thalamus $[10,18,19]$. In contrast, VGLUT1 is expressed in all layers [20] and probably originates from cortico-cortical projections, as pyramidal neurons express VGLUT1 mRNA [21]. Thus, the increased VGLUT2 expression in the cortex of GAERS strengthens the idea of a glutamatergic alteration in the cortex and suggests that this may involve a glutamatergic thalamocortical input. Finally, since VGLUT2 levels are high at birth and rapidly reach adult values $[22,23]$, one may hypothesize that the higher VGLUT2 expression seen in the cortex in adult GAERS, together with the higher levels of synaptophysin, a marker of synaptic plasticity, might correspond to a developmental process that leads to functional synaptic alterations. However, further studies to determine changes in VGLUT expression during the development of GAERS, especially in young animals before the onset of SWD, are needed to explore this hypothesis. Such work will be of interest given the important role of GLU in the regulation of CNS development [24], especially in the induction or elimination of synapses and synapse plasticity $[25,26]$, and the 
developmental cortical morphological alterations described in the WAG/Rij epilepsy model [27].

Together, these observations of alterations in the cortical glutamatergic system in adult GAERS linked to impairment of cortical astrocytic function in terms of GLU reuptake and metabolism are in line with the cortical focus theory of absence epilepsy.

\section{Methods}

\section{Animals}

Male Wistar rats from the Genetic Absence Epilepsy Rats from Strasbourg (GAERS) strain and non-epileptic control (NEC) Wistars were used in this study. GAERS display recurrent generalized absence seizures characterized by bilateral and synchronous SWDs on the EEG, concomitant with behavioral arrest. The animals were kept and used in experiments according to the European Communities Council Directives of November 24, 1986 (86/609/ EEC). For microdialysis studies, the rats $(250-300 \mathrm{~g})$ were anaesthetized with chloral hydrate $(400 \mathrm{mg} / \mathrm{kg} / \mathrm{i} . \mathrm{p}$.) and placed in a stereotaxic frame (David Kopf, USA) with the body temperature maintained close to $37.5^{\circ} \mathrm{C}$ using a heated under-blanket (Harvard Instruments, USA). The skull was exposed and, after drilling appropriate holes, a cannula-guide (CMA12, CMA, Sweden) was implanted either i) in the cortex at a $30^{\circ}$ angle (coordinates relative to the bregma: AP $-3.3 \mathrm{~mm}, \mathrm{~L}+2.3 \mathrm{~mm}, \mathrm{~V}-2.5 \mathrm{~mm}$ below the brain surface) or ii) in the ventrobasal thalamus (coordinates relative to the bregma: AP $-3.5 \mathrm{~mm}, \mathrm{~L}+2 \mathrm{~mm}, \mathrm{~V}$ $6 \mathrm{~mm}$ below the brain surface) according to the atlas of Paxinos \& Watson [28], and secured with stainless steel screws and dental cement. After surgery, the rats were housed in individual cages with food and water ad libitum for 10 days when the microdialysis experiment was performed.

\section{Microdialysis studies}

Concentric microdialysis probes were constructed from regenerated cellulose dialysis tubing (MWCO $6000 \mathrm{Da}$, $225 \mathrm{~mm}$ o.d., $2 \mathrm{~mm}$ active dialysis length) and fused-silica capillary tubing, the body of the probe being made of a 3 $\mathrm{cm} 26 \mathrm{G}$ stainless steel tube, which was glued on a flat probe holder (Harvard, USA). Before implantation, the probes were perfused at a rate of $1 \mu \mathrm{l} / \mathrm{min}$ with artificial cerebrospinal fluid (aCSF) $(149 \mathrm{mM} \mathrm{NaCl}, 2.80 \mathrm{mM} \mathrm{KCl}$, $1.2 \mathrm{mM} \mathrm{MgCl} 2,1.2 \mathrm{mM} \mathrm{CaCl}, 2.78 \mathrm{mM}$ phosphate buffer, $\mathrm{pH}$ 7.4). A probe was implanted into the guidecannula of a freely moving animal placed in the experiment cylinder, the inlet and outlet of the probe being connected to a liquid swivel (mouse model, Instech Solomon USA). The rate of infusion was $1 \mu \mathrm{l} / \mathrm{min}$ for the in vivo evaluation of GLU uptake and $2 \mu \mathrm{l} / \mathrm{min}$ for the "no net flux" experiment. For each dialysis experiments, at least 3 hours was allowed to elapse after microdialysis probe implantation before collection of basal samples. At the end of the experiment, Evans blue was injected via the probe, the rats were sacrificed with a lethal dose of pentobarbital, and the placement of the cannula was verified on the frozen brain [29].

\section{"No net flux" studies}

The basal extracellular concentrations of GLU and GABA were determined by the "no net flux" quantitative microdialysis method [30]. Four different concentrations of GLU $(0,0.5,1$, and $5 \mu \mathrm{mol} / \mathrm{L})$ or GABA $(0,10,50$, and 100 nanomoles/L) $\left(\mathrm{C}_{\text {in }}\right)$, chosen to bracket the expected extracellular concentration, were passed through the microdialysis membrane (each for $16 \mathrm{~min}$, separated by perfusion with aCSF for washing); no sample was collected during the first 10 min of GLU perfusion, allowing a period of equilibration, then three 2-min dialysis samples were collected and stored at $-40^{\circ} \mathrm{C}$ until analyzed for amino acid content.

The concentrations of neurotransmitter in the dialysate samples $\left(\mathrm{C}_{\text {out }}\right)$ obtained during perfusion with the various concentrations of neurotransmitter $\left(\mathrm{C}_{\text {in }}\right)$ were used to construct a linear regression plot of the net change in neurotransmitter $\left(\Delta \mathrm{C}=\mathrm{C}_{\text {in }}-\mathrm{C}_{\text {out }}\right)$ against $\mathrm{C}_{\text {in }}$ for each animal. The true extracellular levels and the extraction fraction of the probe were determined as described by Parsons and Justice [31]. The true extracellular concentration is equal to $\mathrm{C}_{\text {in }}$ when $\Delta \mathrm{C}=0$ and the extraction fraction (Ed) is determined from the slope of the linear regression. Differences in extracellular concentrations or extraction fractions between GAERS and control rats were tested using the F test followed by either Welch's test or Student's t test, as appropriate.

\section{Measurement of amino acid content}

On the day of analysis, $4 \mu \mathrm{L}$ of sample and $4 \mu \mathrm{L}$ of standard solutions were derivatized at room temperature by adding $1.6 \mu \mathrm{L}$ of a mixture $(1: 2: 1 \mathrm{v} / \mathrm{v} / \mathrm{v})$ of $(\mathrm{i})$ internal standard $\left(10^{-4} \mathrm{~mol} / \mathrm{L}\right.$ cysteic acid in $0.117 \mathrm{~mol} / \mathrm{L}$ perchloric acid), (ii) a borate/ $\mathrm{NaCN}$ solution (100:20 v/v mixture of $500 \mathrm{mmol} / \mathrm{L}$ borate buffer, $\mathrm{pH} 8.7$, and $87 \mathrm{mmol} / \mathrm{L}$ $\mathrm{NaCN}$ in water), and (iii) a $2.925 \mathrm{mmol} / \mathrm{L}$ solution of naphthalene-2,3-dicarboxaldehyde in acetonitrile/water $(50: 50 \mathrm{v} / \mathrm{v})$. The samples were then analyzed for amino acid content using an automatic capillary zone electrophoresis $\mathrm{P} / \mathrm{ACE}^{\mathrm{TM}} \mathrm{MDQ}$ system (Beckman, USA) equipped with a ZETALIF laser-induced fluorescence detector (Picometrics, France). Excitation was performed using a He-Cd laser (Liconix, USA) at a wavelength of $442 \mathrm{~nm}$, the emission wavelength being $490 \mathrm{~nm}$. Separations were carried out on a $63 \mathrm{~cm} \times 50 \mu \mathrm{m}$ i.d. fused-silica capillary (Composite Metal Services, Worcester, England) with an effective length of $52 \mathrm{~cm}$. Each day, before the analyses, the capillary was sequentially flushed with $0.25 \mathrm{~mol} / \mathrm{L} \mathrm{NaOH}$ 
(15 min), ultra-pure water (15 $\mathrm{min})$, and running buffer (75 mmol/L sodium borate, $\mathrm{pH} 9.20 \pm 0.02$, containing $10 \mathrm{mmol} / \mathrm{L} \mathrm{HP}-\beta-C D$ and $70 \mathrm{mmol} / \mathrm{L}$ SDS) ( $5 \mathrm{~min}$ ). The separation conditions were an applied voltage of $25 \mathrm{kV}$, hydrodynamic sample injectionOK?? (10 s at $0.6 \mathrm{psi})$, and a temperature, between 36 and $38^{\circ} \mathrm{C}$. The capillary was sequentially flushed for $30 \mathrm{~s}$ each with $0.25 \mathrm{~mol} / \mathrm{L} \mathrm{NaOH}$, ultra-pure water, and running buffer between analyses. Electropherograms were acquired at $15 \mathrm{~Hz}$ using $\mathrm{P} / \mathrm{ACE}^{\mathrm{TM}}$ MDQ software [32].

\section{Measurements of in vivo GLU uptake}

A method based on the uptake of exogenous radioactive GLU [33] was used to evaluate GLU uptake in the cortex and thalamus. Uptake experiments were performed by switching the microdialysis probe perfusion fluid for 10 min to aCSF containing $250 \mu \mathrm{M}{ }^{3} \mathrm{H}-\mathrm{GLU}(15 \mathrm{Ci} / \mathrm{mMol})$ and $120 \mu \mathrm{M}{ }^{14} \mathrm{C}$-mannitol (MAN) $(60 \mathrm{mCi} / \mathrm{mMol})$ (PerkinElmer Life and Analytical Sciences USA), samples of microdialysis probe effluent being collected every $2 \mathrm{~min}$ for dual label scintillation counting. After perfusion with aCSF for 12 min to flush out the radioactive isotopes, the experiment was repeated in the presence of $20 \mathrm{mM}$ threo$\beta$-hydroxyaspartate (THA), a GLU uptake inhibitor.

The relative GLU uptake was determined using the "recovery" vs. "time" curves for 3H-GLU and 14C-MAN, used as the reference, as it is not taken up by cells. The recovery is the counts exiting the probe/input counts ratio (Eq. 1 and 2). The cellular extraction fraction for GLU corrected for mannitol is calculated as in equation 3

$$
\begin{gathered}
\mathrm{R}_{\mathrm{MAN}}=\text { MAN outlet } / \text { MAN inlet } \\
\mathrm{R}_{\mathrm{GLU}}=\mathrm{GLU} \text { outlet } / \mathrm{GLU} \text { inlet } \\
\mathrm{E}_{\mathrm{L}-\mathrm{GLU}}=\mathrm{R}_{\mathrm{MAN}}-\mathrm{R}_{\mathrm{GLU}} / \mathrm{R}_{\mathrm{MAN}}
\end{gathered}
$$

The relative GLU uptake in the presence or absence of THA was calculated for each 2 min of the 10 minute infusion period. Differences in uptake between the mean \pm SEM for GAERS $(\mathrm{N}=12)$ and NEC rats $(\mathrm{N}=12)$ were tested using the unpaired Student's $t$ test and a level of significance of $\mathrm{p}<0.05$.

\section{Western blot analysis}

The experiments were performed on adult GAERS $(n=6)$ and NEC rats $(n=6)$. Dissection of the frontoparietal cortex and thalamus, brain sample preparation, and electrophoresis were performed as described previously (5). Western blotting was performed using 2,5 , or $7.5 \mu \mathrm{g}$ of protein per lane for VGLUT1, VGLUT2, or synaptophysin, respectively, and antibodies against VGLUT1 (1/5000) or VGLUT2 (1/1000) (both from Chemicon, UK) or synaptophysin (1/500) (Boehringer, Mannheim, Germany).
Bound antibody was detected using enzyme catalyzed fluorescence (ECF Western blotting reagent packs; Amersham Pharmacia Biotech, UK) and visualized using a Fluoro-imager (Molecular Dynamics). Fluorescence was quantified using Image Quant (Molecular Dynamics). Linearity of the relationship between the emitted fluorescence and the protein concentration was verified. The results were then expressed as a percentage of control levels (mean \pm SEM) and the data analyzed for statistical significance using the unpaired Student's t test and a level of significance of $\mathrm{p}<0.05$.

\section{Authors' contributions}

$\mathrm{MT}, \mathrm{MDB}$, and SP designed and analyzed the experiments. MT and SP carried out the experiments. MT, MDB, LD, and MFB drafted the manuscript. All authors read and approved the final manuscript.

\section{Acknowledgements}

The capillary electrophoresis P/ACE ${ }^{\mathrm{TM}}$ MDQ system was purchased thanks to a grant from Pfizer. We would like to thank A Nehlig for providing the GAERS and NEC rats and V Sauvinet for technical help. The authors gratefully acknowledge the help of Profs. François Mauguière and Philippe Ryvlin.

The work was supported by the Institut National de la Santé et de la Recherche Médicale, Centre National de la Recherche Scientifique (CNRS), and Université Claude Bernard Lyon I (UCBL). S. Parrot. held an INSERM post-doctoral position.

\section{References}

I. Marescaux C, Vergnes M, Depaulis A: Genetic absence epilepsy in rats from Strasbourg - a review. I Neural Transm Suppl 1992, 35:37-69.

2. Danober L, Deransart C, Depaulis A, Vergnes M, Marescaux C: Pathophysiological mechanisms of genetic absence epilepsy in the rat. Prog Neurobiol 1998, 55(1):27-57.

3. Richards DA, Lemos T, Whitton PS, Bowery NG: Extracellular GABA in the ventrolateral thalamus of rats exhibiting spontaneous absence epilepsy: a microdialysis study. I Neurochem 1995, 65(4): 1674-1680.

4. Sutch RJ, Davies CC, Bowery NG: GABA release and uptake measured in crude synaptosomes from Genetic Absence Epilepsy Rats from Strasbourg (GAERS). Neurochem Int 1999, 34(5):415-425.

5. Dutuit M, Didier-Bazes M, Vergnes M, Mutin M, Conjard A, Akaoka $H$, Belin MF, Touret M: Specific alteration in the expression of glial fibrillary acidic protein, glutamate dehydrogenase, and glutamine synthetase in rats with genetic absence epilepsy. Glia 2000, 32(I): 15-24.

6. Dutuit M, Touret M, Szymocha R, Nehlig A, Belin MF, Didier-Bazes M: Decreased expression of glutamate transporters in genetic absence epilepsy rats before seizure occurrence. J Neurochem 2002, 80(6): 1029-1038.

7. Pumain R, Louvel J, Gastard M, Kurcewicz I, Vergnes M: Responses to $N$-methyl-D-aspartate are enhanced in rats with petit mal-like seizures. J Neural Transm Suppl 1992, 35:97-108.

8. Koerner C, Danober L, Boehrer A, Marescaux C, Vergnes M: Thalamic NMDA transmission in a genetic model of absence epilepsy in rats. Epilepsy Res 1996, 25(1): II-19.

9. Dufour F, Nalecz KA, Nalecz MJ, Nehlig A: Modulation of absence seizures by branched-chain amino acids: correlation with brain amino acid concentrations. Neurosci Res 2001, 40(3):255-263.

10. Bellocchio EE, Reimer RJ, Fremeau RT Jr, Edwards RH: Uptake of glutamate into synaptic vesicles by an inorganic phosphate transporter. Science 2000, 289(548 I):957-960. 
II. Janz R, Sudhof TC, Hammer RE, Unni V, Siegelbaum SA, Bolshakov VY: Essential roles in synaptic plasticity for synaptogyrin I and synaptophysin I. Neuron I999, 24(3):687-700.

12. Hinz B, Becher A, Mitter D, Schulze K, Heinemann U, Draguhn A, Ahnert-Hilger G: Activity-dependent changes of the presynaptic synaptophysin-synaptobrevin complex in adult rat brain. Eur J Cell Biol 200I, 80(10):6I5-6I9.

13. Pinault $D$ : Cellular interactions in the rat somatosensory thalamocortical system during normal and epileptic 5-9 $\mathbf{~ H z}$. J Physiol 2003, 552(3):88I-905.

14. Meeren H, van Luijtelaar G, Lopes da Silva F, Coenen A: Evolving concepts on the pathophysiology of absence seizures: the cortical focus theory. Arch Neurol 2005, 62(3):37I-376.

15. Manning JP, Richards DA, Leresche N, Crunelli V, Bowery NG: Cortical-area specific block of genetically determined absence seizures by ethosuximide. Neuroscience 2004, I 23(I):5-9.

16. Anderson CM, Swanson RA: Astrocyte glutamate transport: review of properties, regulation, and physiological functions. Glia 2000, 32(I): I- 14.

17. Danbolt NC: Glutamate uptake. Prog Neurobiol 200I, 65(1): $1-105$

18. Hisano S, Hoshi K, Ikeda Y, Maruyama D, Kanemoto M, Ichijo H, Kojima I, Takeda J, Nogami H: Regional expression of a gene encoding a neuron-specific $\mathrm{Na}(+)$-dependent inorganic phosphate cotransporter (DNPI) in the rat forebrain. Brain Res Mol Brain Res 2000, 83(I-2):34-43.

19. Kaneko T, Fujiyama F, Hioki H: Immunohistochemical localization of candidates for vesicular glutamate transporters in the rat brain. J Comp Neurol 2002, 444(I):39-62.

20. Varoqui H, Schafer MK, Zhu H, Weihe E, Erickson JD: Identification of the differentiation-associated $\mathbf{N a}+/ \mathrm{PI}$ transporter as a novel vesicular glutamate transporter expressed in a distinct set of glutamatergic synapses. J Neurosci 2002, 22(I): I 42-I 55.

21. Ni B, Wu X, Yan GM, Wang J, Paul SM: Regional expression and cellular localization of the $\mathrm{Na}(+)$-dependent inorganic phosphate cotransporter of rat brain. J Neurosci 1995, I 5(8):5789-5799.

22. Minelli A, Edwards RH, Manzoni T, Conti F: Postnatal development of the glutamate vesicular transporter VGLUTI in rat cerebral cortex. Brain Res Dev Brain Res 2003, I40(2):309-3I4.

23. Boulland JL, Qureshi T, Seal RP, Rafiki A, Gundersen V, Bergersen LH, Fremeau RT Jr, Edwards RH, Storm-Mathisen J, Chaudhry FA: Expression of the vesicular glutamate transporters during development indicates the widespread corelease of multiple neurotransmitters. J Comp Neurol 2004, 480(3):264-280.

24. LaMantia AS: The usual suspects: GABA and glutamate may regulate proliferation in the neocortex. Neuron 1995, 15(6): $1223-1225$

25. Cornell-Bell AH, Thomas PG, Smith SJ: The excitatory neurotransmitter glutamate causes filopodia formation in cultured hippocampal astrocytes. Glia 1990, 3(5):322-334.

26. Monnerie H, Shashidhara S, Le Roux PD: Effect of excess extracellular glutamate on dendrite growth from cerebral cortical neurons at 3 days in vitro: Involvement of NMDA receptors. J Neurosci Res 2003, 74(5):688-700.

27. Karpova AV, Bikbaev AF, Coenen AML, van Luijtelaar G: Morphometric Golgi study of cortical location in WAG/Rij rats: the cortical focus theory. Neurosci Res 2005:1 19-128.

28. Paxinos G, Watson C: The rat brain in stereotaxic coordinates, New York. 4th edition. 1998.

29. Bert L, Favale D, Jego G, Greve P, Guilloux JP, Guiard BP, Gardier AM, Suaud-Chagny MF, Lestage P: Rapid and precise method to locate microdialysis probe implantation in the rodent brain. J Neurosci Methods 2004, I 40(I-2):53-57.

30. Justice JB: Quantitative microdialysis of neurotransmitters. J Neurosci Methods 1993, 48(3):263-276.

31. Parsons $\mathrm{LH}$, Justice JB Jr: Quantitative approaches to in vivo brain microdialysis. Crit Rev Neurobiol 1994, 8(3):189-220.

32. Sauvinet V, Parrot S, Benturquia N, Bravo-Moraton E, Renaud B, Denoroy L: In vivo simultaneous monitoring of gamma-aminobutyric acid, glutamate, and L-aspartate using brain microdialysis and capillary electrophoresis with laserinduced fluorescence detection: Analytical developments and in vitro/in vivo validations. Electrophoresis 2003, 24(18):3187-3196.
33. Alexander GM, Grothusen JR, Gordon SW, Schwartzman RJ: Intracerebral microdialysis study of glutamate reuptake in awake, behaving rats. Brain Res 1997, 766(I-2): I-I0.
Publish with Biomed Central and every scientist can read your work free of charge

"BioMed Central will be the most significant development for disseminating the results of biomedical research in our lifetime. "

Sir Paul Nurse, Cancer Research UK

Your research papers will be:

- available free of charge to the entire biomedical community

- peer reviewed and published immediately upon acceptance

- cited in PubMed and archived on PubMed Central

- yours - you keep the copyright 